\title{
RISK-INDUCED EARLY HATCHING IN SALMONIDS
}

\author{
Claus Wedekind ${ }^{1,2,3,4}$ AND Rudolf MÜlleR ${ }^{1}$ \\ ${ }^{1}$ Swiss Federal Institute for Environmental Science and Technology, EAWAG, 6047 Kastanienbaum, Switzerland \\ ${ }^{2}$ Division of Conservation Biology, Zoological Institute, University of Bern, 3012 Bern, Switzerland \\ ${ }^{3}$ Program for Evolutionary Dynamics, and Department of Organismic and Evolutionary Biology, Harvard University, \\ Cambridge, Massachusetts 02138 USA
}

\begin{abstract}
Many ontogenetic niche shifts are phenotypically plastic and with their timing dependent on the perceived risks and benefits for the individual. In fish, hatching can be induced by oxygen shortage or the presence of egg predators or pathogens. However, little is known about the embryos' ability to avoid desiccation by hatching earlier. We simulated an increased risk by exposing some embryonated eggs to low water levels and compared them to control eggs kept deeper in the water. We tested eggs of arctic charr (Salvelinus alpinus), brown trout (Salmo trutta), and of small and large ecotypes of alpine whitefish (Coregonus sp.). During exposure, the apparently more risky environment induced higher rates of early hatching in all taxa tested. We suggest that the early hatching is either an adaptation of salmonids to risky environments or an accidental by-product that did not get counterselected because of its benefits to the fish larvae.
\end{abstract}

Key words: egg development; induced defense; life history; niche shift; phenotypic plasticity; salmonid; timing of hatching.

\section{INTRODUCTION}

Life history models normally assume that animals can detect and react to subtle temporal and spatial variation in the environment (Roff 1992, Stearns 1992). The reaction may be behavioral (Kiesecker et al. 1999, Belden et al. 2000, Mirza and Chivers 2001, Wisenden and Millard 2001, deVito 2003), developmental, morphological, or physiological (Agrawal et al. 1999, Van Buskirk and Schmidt 2000, Kopp and Tollrian 2003), and it can involve an ontogenetic shift in niche or life history (Boersma et al. 1998). Hatching is an ontogenetic niche shift. According to life-history theory, increased risk of larval mortality would favor delayed hatching, while relatively high egg mortality would favor early hatching (Werner and Gilliam 1984, Werner 1986). A recent series of papers, mostly on amphibians, have revealed that the timing of hatching can be phenotypically plastic in reaction to predators (Sih and Moore 1993, Warkentin 1995, Moore et al. 1996, Warkentin 2000a, $b$, Chivers et al. 2001, Saenz et al. 2003) or pathogens (Warkentin et al. 2001). In salmonid fish, hatching timing varies between species

Manuscript received 16 November 2004; revised 22 February 2005; accepted 1 March 2005. Corresponding Editor: S. P. Lawler.

${ }^{4}$ E-mail: wedekind@fas.harvard.edu and with incubation temperature (Jungwirth and Winkler 1984), and there can be considerable variation within sibships (C. Wedekind and R. Müller, unpublished data). However, there is comparatively little known about phenotypic plasticity in hatching. Recently, Kusch and Chivers (2004) reported the first empirical evidence that a fish can alter hatching time in response to predation cues. Czerkies et al. (2001) found that oxygen stress can increase early hatching rates, and Wedekind (2002) found induced hatching in response to an infectious egg disease. Here, we test whether eggs hatch earlier in response to an increased risk of desiccation.

At low water levels, fish eggs risk drying out or damage by UV radiation (Kouwenberg et al. 1999, Battini et al. 2000). Motivated by opportunistic observations during another study (C. Wedekind and R. Müller, unpublished manuscript), we performed a series of experiments to test if fish embryos can respond to low water levels by hatching earlier, allowing escape into deeper water. We tested eggs of four salmonid species and ecotypes, including arctic charr (Salvelinus alpinus), brown trout (Salmo trutta), and both small and large ecotypes of alpine whitefish (Coregonus sp.; see Douglas et al. 1999 for the taxonomy of alpine whitefish ecotypes). 


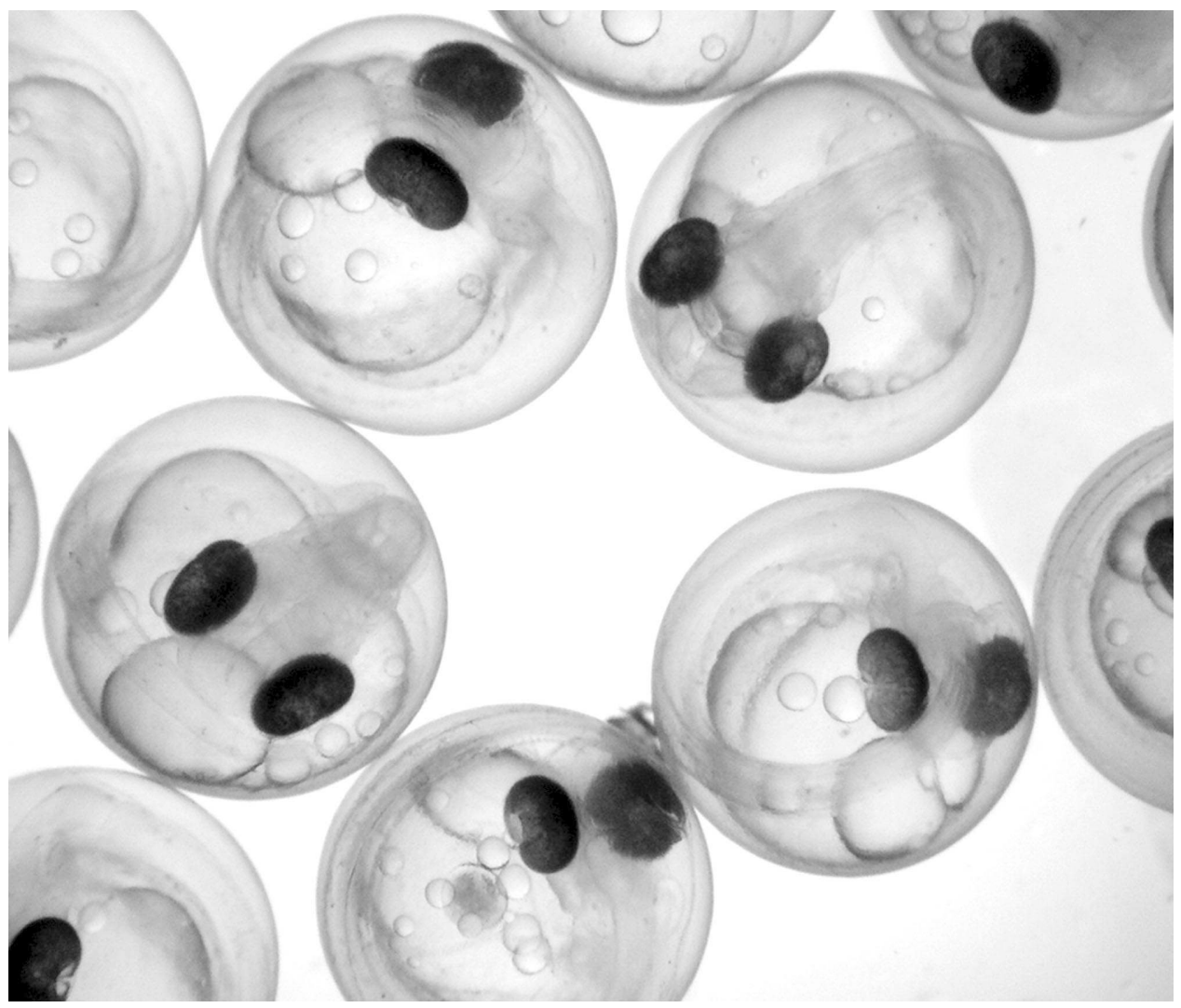

Plate 1. Small-type alpine whitefish soon ready to hatch. Photo credit: R. Müller.

\section{Methods}

To experimentally assess hatching responses to water depth, we exposed embryonated eggs to two different depths. Plexiglas plates were fixed at an angle within experimental tanks. The plates had two rows of drilled coniform indentations, so that two rows of eggs could be held in the indentations at different depths. After an incubation period, we recorded the number of eggs that hatched in the upper and the lower row, removed the hatchlings, and placed the unhatched eggs in a new Petri dish to test whether they would hatch later. All experiments took place at $6^{\circ} \mathrm{C}$ in a climate chamber.

For the large eggs of arctic charr and brown trout (mean egg diameter $\pm \mathrm{SD}=5.2 \pm 0.27 \mathrm{~mm}$ and 5.6 $\pm 0.17 \mathrm{~mm}$, respectively), the egg-holding indentations were $2.1 \mathrm{~mm}$ deep and $4.3 \mathrm{~mm}$ in diameter at the base ( $n=9$ per row). The upper row of eggs was just below the water surface (the surface tension appeared to keep the eggs submerged); the lower row was positioned 4 $\mathrm{mm}$ deeper. The water volume of the experimental tank was $50 \mathrm{~mL}$. For eggs of the small-type and the largetype whitefish (mean egg diameter $=2.3 \pm 0.11 \mathrm{~mm}$ and $2.7 \pm 0.06 \mathrm{~mm}$, respectively), the indentations were $0.7 \mathrm{~mm}$ deep and $3.0 \mathrm{~mm}$ in diameter at the base
( $n=20$ per row). The upper row of eggs was again just below the water surface (submerged by surface tension); the lower row was positioned $12 \mathrm{~mm}$ deeper. The total water volume of the experimental tank was $250 \mathrm{~mL}$.

Adult small-type whitefish were caught from Lake Lucerne (central Switzerland) during their spawning season in November (see Plate 1). We stripped these fish for their gametes to produce various sibships for another study (C. Wedekind and R. Müller, unpublished manuscript). Shortly after fertilization, the eggs were washed in sterilized, aerated, $6^{\circ} \mathrm{C}$ lake water. We distributed the eggs of each sibship to uncovered Petri dishes (diameter $=8.6 \mathrm{~cm}$, water level $=$ about $1 \mathrm{~cm}$, i.e., $50 \mathrm{~mL}, 108.3 \pm 2.9$ [mean $\pm \mathrm{SE}]$ ) and reared them at constant $6^{\circ} \mathrm{C}$ in a climate chamber until hatching (detailed methods in Wedekind et al. 2001). On day 76 after fertilization, we randomly chose one Petri dish (i.e., a full-sib batch of eggs) in which the first hatchlings could be observed. We randomly picked 40 eggs from this batch and used them immediately for one 28$\mathrm{h}$ experiment.

Adult large-type whitefish were caught from Lake Lucerne during their spawning season in December. We 


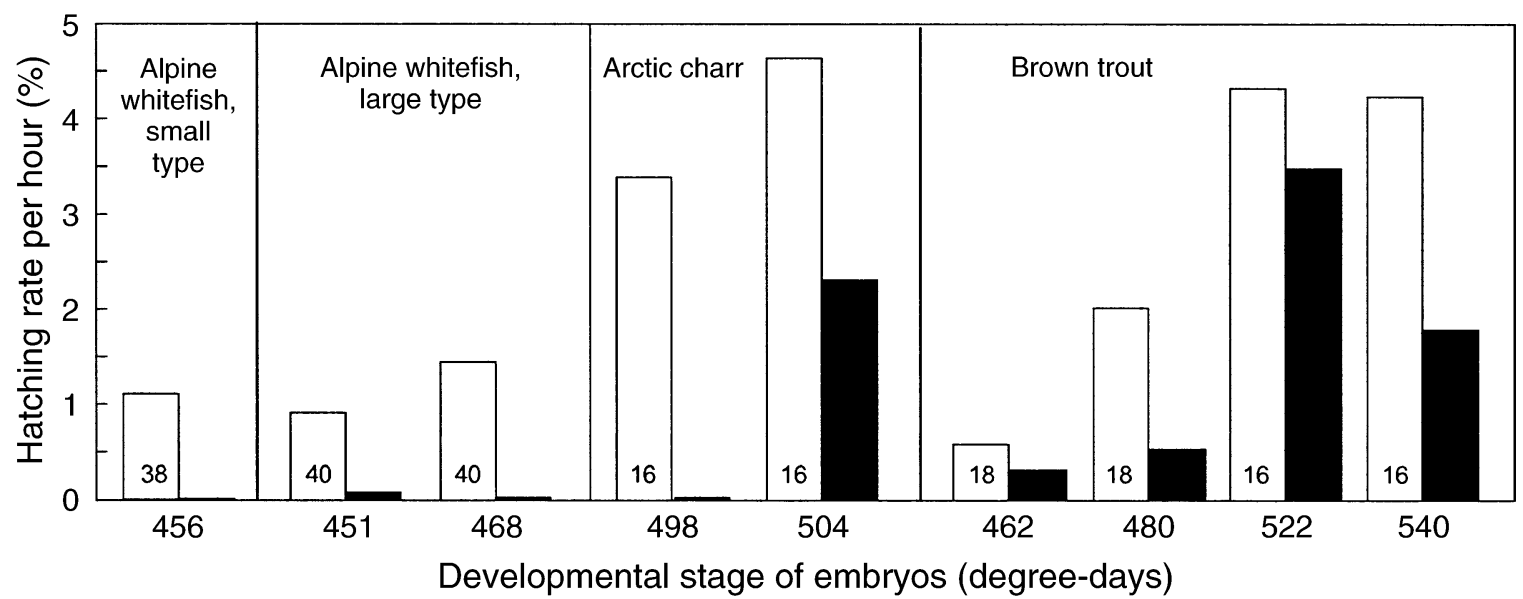

Fig. 1. Hatching rate (percentage per hour) of different types of salmonid eggs in the experiments and relative to their developmental stage. The developmental stage is given here as degree-days, i.e., age (in days) $\times$ rearing temperature (in ${ }^{\circ} \mathrm{C}$ ). The eggs were either positioned near the water surface (simulating the risk of drying out; open bars) or some millimeters below the water surface (safer positions; solid bars). The sample size per experiment is given in the open bars.

stripped them for their gametes and fertilized the eggs from five females with a mixture of sperm from 30 males. All eggs were then transferred to a Zug jar, where they were reared in a steady flow of sand-filtered (i.e., nonsterilized) water from Lake Lucerne (about 60 $\mathrm{L} / \mathrm{h}$ at, on average, $8.5^{\circ} \mathrm{C}$ ). This procedure is widespread among fish hatcheries. It usually leads, as in our case, to some micropathogen-connected embryo mortality. Immediately before the experiment, we transferred a sample of eggs to the $6^{\circ} \mathrm{C}$ climate chamber, removed the dead and obviously infected eggs, and washed the healthy-looking eggs several times in sterilized lake water. We performed two experiments with 40 eggs each (first experiment, $48 \mathrm{~h}$; second experiment, $24 \mathrm{~h})$.

We caught arctic charr from Lake Lucerne during their spawning season in November. We fertilized the eggs of one female with a mixture of sperm from two males, washed the eggs in sterilized lake water, and reared them at constant $6^{\circ} \mathrm{C}$ in 13 Petri dishes (Wedekind and Müller 2004). First hatchlings were observed on day 83 after fertilization. We started the first experiment (lasting $18.5 \mathrm{~h}$ ) on that day and a second experiment (lasting $21.5 \mathrm{~h}$ ) one day later.

Adult brown trout were caught in the Enziwigger River (in the Swiss Midlands) at the beginning of their spawning season in November. The eggs of one female were fertilized by sperm of four males and raised in separate half-sib batches in Petri dishes as in Wedekind and Müller (2004). Experiments lasted for 72 h, 45 h, $23 \mathrm{~h}$, and $24 \mathrm{~h}$, at succeeding developmental stages.
In some experiments (the ones with small-type whitefish and the arctic charr, and the last two with brown trout), one unhatched egg each could not be attributed to a row because it had rolled out of its indentation. We therefore reduced the sample size of each row by one and counted only eggs that were still in their indentations. We used stepwise log-likelihood models and tested the effects of egg position and experiment separately. However, pooling all data per species or ecotype and testing them in likelihood ratio $\chi^{2}$ tests ( $\mathrm{df}=1$ each) would lead to the same qualitative results with regard to egg position.

\section{RESUlts}

Fig. 1 summarizes the results. In all species or ecotypes, the eggs near the surface were more likely to hatch than the control eggs during the observational period (stepwise log-likelihood models, testing the effects of position only; $\mathrm{df}=1$ each; small-type whitefish, $\chi^{2}=9.4, P=0.002$; large-type whitefish, $\chi^{2}=$ 19.6, $P<0.001$; arctic charr, $\chi^{2}=10.2, P=0.001$; brown trout, $\left.\chi^{2}=14.4, P<0.001\right)$. The effects of experimental run are significant in arctic charr and brown trout, with $P$ always $<0.05$, but not significant in large-type whitefish. Three large-type whitefish eggs that had not hatched during the experiment were obviously infected and died before hatching. All other eggs that had not hatched during the experiment survived and hatched within few days.

\section{DISCUSSION}

Embryos could hatch earlier to escape egg-stage risks or delay hatching to avoid post-hatching risks (Sih 
and Moore 1993, Warkentin 1995). Initial evidence that the timing of hatching in fish is plastic in response to perceived risks and benefits comes from recent studies that showed responses of fish embryos to predation cues (Kusch and Chivers 2004), to oxygen shortage (Czerkies et al. 2001), and to cues indicating an infectious disease (Wedekind 2002). Here, we demonstrate that eggs from several salmonid species or ecotypes hatch earlier in response to low water levels, thereby potentially avoiding the risks of drying out.

Brown trout typically spawn in small streams with variable water levels. Hence, eggs of brown trout are likely to face low water levels during their development. The same could be true for eggs of our largetype alpine whitefish that spawn near the shore of alpine lakes. However, the populations of small-type whitefish and arctic charr from which we took our samples both spawn in the deeper regions of alpine lakes and are very unlikely to be exposed to low water levels. We nevertheless found a reaction to low water levels in all of the four species/ecotypes that we tested. Moreover, the eggs of brown trout and large-type whitefish did not seem to react more pronounced to our experimental treatment than the arctic charr or the small-type whitefish. This could mean that the observed reaction is an ancient adaptation in salmonids that did not get lost in populations that spawn in deeper water, possibly because such plasticity may not be costly to maintain. Alternatively, it could be that the early hatching in low water is an accidental by-product of some chemical or physiological change that happens to fish eggs in low water. Such a by-product is not likely to get counterselected if it is, overall, beneficial to the larvae (which is clearly the case if unhatched embryos would dry out).

Our experimental exposure to low water levels did not appear to alter mortality rates among the eggs or freshly hatched larvae. With the few exceptions of some large-type whitefish eggs from nonsterile rearing conditions infected by micropathogens, all nonhatched eggs in the experiment hatched later, i.e., mortality among the experimental eggs that were kept in sterilized water was zero. This confirms that the embryos are ready and able to survive as hatchlings for some time before they would normally hatch if left undisturbed (Valdimarsson et al. 2002).

Warkentin (1995) found that red-eyed treefrogs (Agalychnis callidryas) that hatched earlier in response to disturbance were more vulnerable to predation by a poecillid fish (Brachyraphis rabdophora) and a shrimp (Macrobrachium americanum). Other authors who studied ontogenetic shifts comparable to hatching, such as nest emergence (Spencer et al. 2001) and metamorphosis (de Vito et al. 1999), suggest that there is an advantage of synchronizing these shifts simply because grouping dilutes the per capita predation risk. If so, the ideal hatching time would be at the time when most surrounding eggs hatch, or possibly even later. This could lead to a kind of waiting game, i.e., the kind of game that a group of wildebeest (Connochaetes gnou) experience when waiting for the first ones to jump into a crocodile-infested river that needs to be crossed. Hence, from a purely physiological point of view, the timing of hatching of our undisturbed control eggs may not be optimal but could be rather late with regard to embryo development. However, if earlier hatching leads to earlier arriving in a new environment, a socalled "prior residence advantage" (i.e., individuals who arrive first in a new habitat tend to obtain and later defend the most profitable sites, see Harwood et al. 2003, Brännäs et al. 2004), may partly compensate for any possible costs of early hatching.

In conclusion, the present study and other recent studies on risk-induced hatching suggest that salmonids have a considerable plasticity in their hatching characteristics and that the timing of hatching is not only dependent of the rate of development, but also on how the embryo perceives the risks and benefits of leaving versus staying in the egg. Whether the induced early hatching imposes costs on the individuals, as well as the obvious benefits, may be dependent on the ecological environment (e.g., the presence and hunger state of predators). Individuals that hatch early in response to perceived risks may not necessarily be developmentally premature.

\section{ACKNOWLEDGMENTS}

We thank N. and A. Hofer, J. Muggli, and P. Amrein for catching and providing the fish; A. Steffen, M. Bia, and L. Wedekind for technical assistance; and S. Lawler and two reviewers for valuable comments on the manuscript. C. Wedekind is supported by a Sarah and Daniel Hrdy visiting fellowship and by the Swiss National Science Foundation.

\section{Literature Cited}

Agrawal, A. A., C. Laforsch, and R. Tollrian. 1999. Transgenerational induction of defences in animals and plants. Nature 401:60-63.

Battini, M., V. Rocco, M. Lozada, B. Tartarotti, and H. E. Zagarese. 2000. Effects of ultraviolet radiation on the eggs of landlocked Galaxias maculates (Galaxiidae, Pisces) in northwestern Patagonia. Freshwater Biology 44:547-552.

Belden, L. K., E. L. Wildy, A. C. Hatch, and A. R. Blaustein. 2000. Juvenile western toads, Bufo boreas, avoid chemical cues of snakes fed juvenile, but not larval, conspecifics. Animal Behaviour 59:871-875.

Boersma, M., P. Spaak, and L. De Meester. 1998. Predatormediated plasticity in morphology, life history, and behavior of Daphnia: the uncoupling of responses. American Naturalist 152:237-248.

Brännäs, E., S. Jonsson, and K. Brännäs. 2004. Densitydependent effects of prior residence and behavioural strategy on growth of stocked brown trout (Salmo trutta). Canadian Journal of Zoology 82:1638-1646. 
Chivers, D. P., J. M. Kiesecker, A. Marco, J. DeVito, M. T. Anderson, and A. R. Blaustein. 2001. Predator-induced life history changes in amphibians: egg predation induces hatching. Oikos 92:135-142.

Czerkies, P., P. Brzuzan, K. Kordalski, and M. Luczynski. 2001. Critical partial pressures of oxygen causing precocious hatching in Coregonus lavaretus and $C$. albula embryos. Aquaculture 196:151-158.

deVito, J. 2003. Metamorphic synchrony and aggregation as antipredator responses in American toads. Oikos 103:7580

de Vito, J., D. P. Chivers, J. M. Kiesecker, L. K. Belden, and A. R. Blaustein. 1999. Effects of snake predation on aggregation and metamorphosis of Pacific treefrog (Hyla regilla) larvae. Journal of Herpetology 33:504-507.

Douglas, M. R., P. C. Brunner, and L. Bernatchez. 1999. Do assemblages of Coregonus (Teleostei: Salmoniformes) in the Central Alpine region of Europe represent species flocks? Molecular Ecology 8:589-603.

Harwood, A. J., S. W. Griffiths, N. B. Metcalfe, and J. D. Armstrong. 2003. The relative influence of prior residency and dominance on the early feeding behaviour of juvenile Atlantic salmon. Animal Behaviour 65:1141-1149.

Jungwirth, M., and H. Winkler. 1984. The temperature dependence of embryonic development of grayling (Thymallus thymallus), Danube salmon (Hucho hucho), arctic char (Salvelinus alpinus) and brown trout (Salmo trutta fario) Aquaculture 38:315-327.

Kiesecker, J. M., D. K. Skelly, K. H. Beard, and E. Preisser. 1999. Behavioral reduction of infection risk. Proceedings of the National Academy of Sciences (USA) 96:91659168.

Kopp, M., and R. Tollrian. 2003. Reciprocal phenotypic plasticity in a predator-prey system: inducible offences against inducible defences? Ecology Letters 6:742-748.

Kouwenberg, J. H. M., H. I. Browman, J. J. Cullen, R. F Davis, J. F. St-Pierre, and J. A. Runge. 1999. Biological weighting of ultraviolet $(280-400 \mathrm{~nm})$ induced mortality in marine zooplankton and fish. I. Atlantic cod (Gadus morhua) eggs. Marine Biology 134:269-284.

Kusch, R. C., and D. P. Chivers. 2004. The effects of crayfish predation on phenotypic and life-history variation in fathead minnows. Canadian Journal of Zoology-Revue Canadienne De Zoologie 82:917-921.

Mirza, R. S., and D. P. Chivers. 2001. Are chemical alarm cues conserved within salmonid fishes? Journal of Chemical Ecology 27:1641-1655.

Moore, R. D., B. Newton, and A. Sih. 1996. Delayed hatching as a response of streamside salamander eggs to chemica cues from predatory sunfish. Oikos 77:331-335.
Roff, D. A. 1992. The evolution of life histories. Chapman and Hall, New York, New York, USA.

Saenz, D., J. B. Johnson, C. K. Adams, and G. H. Dayton. 2003. Accelerated hatching of southern leopard frog (Rana sphenocephala) eggs in response to the presence of a crayfish (Procambarus nigrocinctus) predator. Copeia 2003: 646-649.

Sih, A., and R. D. Moore. 1993. Delayed hatching of salamander eggs in response to enhanced larval predation risk. American Naturalist 142:947-960.

Spencer, R. J., M. B. Thompson, and P. B. Banks. 2001. Hatch or wait? A dilemma in reptilian incubation. Oikos 93:401406.

Stearns, S. C. 1992. The evolution of life histories. Oxford University Press, Oxford, UK.

Valdimarsson, S. K., S. Skulason, and S. S. Snorrason. 2002. The relationship between egg size and the rate of early development in arctic charr, Salvelinus alpinus. Environmental Biology of Fishes 65:463-468.

Van Buskirk, J., and B. R. Schmidt. 2000. Predator-induced phenotypic plasticity in larval newts: trade-offs, selection, and variation in nature. Ecology 81:3009-3028.

Warkentin, K. M. 1995. Adaptive plasticity in hatching agea response to predation risk trade-offs. Proceedings of the National Academy of Sciences (USA) 92:3507-3510.

Warkentin, K. M. 2000a. Hatching as a defense against egg predators: the role of vibrational cues. American Zoologist 40:1250-1251.

Warkentin, K. M. 2000b. Wasp predation and wasp-induced hatching of red-eyed treefrog eggs. Animal Behaviour 60: 503-510.

Warkentin, K. M., C. R. Currie, and S. A. Rehner. 2001. Eggkilling fungus induces early hatching of red-eyed treefrog eggs. Ecology 82:2860-2869.

Wedekind, C. 2002. Induced hatching to avoid infectious egg disease in whitefish. Current Biology 12:69-71.

Wedekind, C., and R. Müller. 2004. The experimental rearing of large salmonid eggs in Petri dishes. Functional Ecology 18: $138-140$.

Wedekind, C., R. Müller, and H. Spicher. 2001. Potential genetic benefits of mate selection in whitefish. Journal of Evolutionary Biology 14:980-986.

Werner, E. E. 1986. Amphibian metamorphosis-growthrate, predation risk, and the optimal size at transformation. American Naturalist 128:319-341.

Werner, E. E., and J. F. Gilliam. 1984. The ontogenetic niche and species interactions in size structured populations. Annual Review of Ecology and Systematics 15:393-425.

Wisenden, B. D., and M. C. Millard. 2001. Aquatic flatworms use chemical cues from injured conspecifics to assess predation risk and to associate risk with novel cues. Animal Behaviour 62:761-766. 